\title{
Comunidades como espaços de intervenção pedagógica um estudo da docência no ensino médio
}

\author{
ROBERTO RAFAEL DIAS DA SILVA \\ Universidade Federal da Fronteira Sul, \\ Erechim, RS, Brasil
}

\section{RESUMO}

O presente texto trata dos modos contemporâneos de constituição da docência no ensino médio no Brasil. O eixo da investigação esteve centrado em examinar como a seguridade, enquanto tecnologia de governo, opera na regulação da conduta dos professores do ensino médio, produzindo uma pedagogia das proteções que toma as comunidades como espaço privilegiado de intervenção. A revista Carta na Escola, em suas publicações desenvolvidas entre os anos de 2005 e 2010, foi a materialidade investigativa escolhida para este estudo. $\mathrm{O}$ gerenciamento dos riscos coletivos e a autopropulsão ao medo foram as estratégias examinadas. A partir dos estudos foucaultianos, conclui-se que a produção de uma docência comunitária implica o desencadeamento de práticas de governo de si e dos outros que visam a uma intervenção qualificada no ensino médio com base nos valores da sustentabilidade ambiental e da justiça social, desencadeando uma configuração docente politicamente útil e socialmente relevante.

PALAVRAS-CHAVE

docência; ensino médio; comunidades; estudos foucaultianos. 


\title{
COMMUNITY AS A SPACE FOR EDUCATIONAL INTERVENTION: A STUDY OF TEACHING IN HIGH SCHOOL
}

\begin{abstract}
This paper deals with the contemporary modes of teaching in high schools in Brazil. The research was focused on examining social security, as an instrument of government, in regulating the conduct of high school teachers, producing a pedagogy that takes the protection of communities as a privileged space for intervention. The magazine Carta na Escola, in their publications between the years 2005 and 2010, used investigative material for this study. The management of collective risks and self-induced fear were the strategies examined. According to the Foucauldian Studies, it is concluded that the delivery of community teaching involves the triggering of governance practices that aim qualified intervention in high school with values of environmental sustainability and social justice, providing teaching which is politically useful and socially relevant.
\end{abstract}

\section{KEYWORDS}

teaching; high school; communities; foucaultian studies.

\section{COMUNIDADES COMO ESPACIOS DE INTERVENCIÓN PEDAGÓGICA: UN ESTUDIO DE LA DOCENCIA EN LA ESCUELA SECUNDARIA}

\section{RESUMEN}

El presente texto trata de los modos contemporáneos de constitución de la docencia en la escuela secundaria en Brasil. El eje de la investigación se centró en examinar de qué manera la seguridad -como una tecnología de gobierno- opera en la regulación de la conducta de los profesores de escuelas secundarias, produciendo una pedagogía de las protecciones que toma a las comunidades como espacio privilegiado de intervención. La revista Carta na Escola, en sus publicaciones desarrolladas entre los años 2005 y 2010, fue la elegida como material de investigación para este estudio. Las estrategias examinadas fueron la gestión de los riesgos colectivos y la autopropulsión del miedo. A partir de los estudios foucaultianos se concluye que la producción de una docencia comunitaria implica el desencadenamiento de prácticas de gobierno de sí mismo y de los otros, prácticas estas destinadas a una intervención cualificada en la escuela secundaria a partir de los valores de la sostenibilidad ambiental y de la justicia social, provocando una configuración docente políticamente útil y socialmente relevante.

PALABRAS CLAVE

docencia; escuela secundaria; comunidades; estudios foucaultianos. 
Procuram-se grupos de alunos e professores inquietos. Mais ainda: insatisfeitos com algum aspecto do lugar onde vivem ou estudam e dispostos a fazer algo para mudar. Qual escola não quer melhorar sua própria comunidade? Qual comunidade não quer uma escola que a abrace, envolvendo-a em uma proposta amparada na ideia de ser mais sustentável? O que significa, também, tornar-se mais forte, mais bem preparada para lidar com seus próprios problemas a partir de soluções locais. Carta na Escola, 2008a, p. 2

Considerar as comunidades como espaços de intervenção pedagógica constitui-se, contemporaneamente, como um dos grandes sentidos das políticas de escolarização. Idealizar uma instituição de ensino que não fique circunscrita ao espaço delimitado por seus muros, que produza sentido na vida dos estudantes e de suas comunidades, apresenta-se como a grande utopia pedagógica brasileira no início do século XXI. A organização do trabalho escolar, tanto na gestão de seus processos pedagógicos, quanto na seleção dos conhecimentos escolares, tem atribuído centralidade à participação comunitária. A edição de número 25 da revista Carta na Escola, em seu editorial, do qual utilizei um fragmento como epígrafe para este texto, enuncia e visibiliza uma intencionalidade pedagógica que foi multiplicada ao longo de todo aquele ano de trabalho. Em 2008, ocorreu o lançamento do primeiro prêmio "Minha Comunidade Sustentável", concorrência organizada pela revista e da qual todas as escolas do país estavam sendo convidadas a participar. O editorial, mais que simplesmente fazer a convocatória para um concurso, situa-nos no interior de uma tecnologia de governo da docência no ensino médio, a qual nomearei neste artigo, com inspiração nos estudos foucaultianos, como "tecnologia de seguridade".

Essa tecnologia toma como campo de ação um perfil de professores e de estudantes, posiciona-os de forma comprometida com a transformação do lugar onde vivem e, consequentemente, torna visível um espaço de atuação singular - a comunidade. Sem entrar na discussão bastante significativa nas ciências sociais sobre o significado deste conceito, utilizo-o no contexto desta analítica como o espaço onde as escolas estão inseridas.

Também utilizo a ideia de comunidade para expressar a preocupação contemporânea em produzir soluções locais para as diferentes problemáticas de nosso tempo. Assim, é possível apontar imediatamente que a referida tecnologia de seguridade, ao considerar as comunidades como espaços de intervenção, sugere a produção de uma docência no ensino médio com perfil bastante peculiar - disposição a criar soluções para o mundo à sua volta -, dessa forma tornando-se politicamente útil em uma lógica de Estado neoliberal.

A teorização pedagógica produzida nas últimas duas décadas tem sido fértil em novas imagens acerca dos espaços educativos. Ideias como cidades educadoras, comunidades de aprendizagem ou mesmo pedagogias cidadãs tornaram-se muito comuns nesse cenário. Pretendo problematizar algumas estratégias que entram em jogo quando a pedagogia contemporânea passa a estender sua preocupação para 
outros campos, para além das salas de aula. Esse prolongamento da dimensão pedagógica a toda a esfera da urbanidade é um movimento bastante significativo na produção moderna desse campo de saber. Faz-se possível visibilizar a emergência dessas articulações no pensamento pedagógico brasileiro (autointitulado progressista), produzido na segunda metade do último século.

Para o tratamento da questão mobilizadora do estudo do qual este artigo deriva - a constituição da docência no ensino médio no Brasil contemporâneo -, tomei como materialidade empírica um conjunto de 45 edições da revista Carta na Escola, publicação produzida pela Editora Confiança desde 2005, derivada da revista informativa Carta Capital e dirigida aos professores do ensino médio. Por meio de uma leitura atenta de seus diferentes textos, imagens, composições gráficas e anúncios publicitários, foi possível notar o modo como esse material enunciava e visibilizava a constituição de uma docência com características específicas. Com isso, não intencionava afirmar que o referido artefato midiático produzia ações verticais sobre as subjetividades docentes; mas, antes disso, interpelava e seduzia os sujeitos para que, no uso de suas liberdades, assumissem determinadas formas de pensar e agir.

Para a realização do referido estudo, propus-me a estabelecer uma analítica de governo (Dean, 1999) e interrogar por tecnologias de governo. Essa abordagem inspirou-se na produção teórica de Michel Foucault, sobretudo em seus estudos acerca do conceito de governamentalidade. ${ }^{1} \mathrm{~A}$ aproximação desse pensador implicou algumas prerrogativas metodológicas que orientaram a produção do estudo. Pelo menos três dessas questões podem ser apontadas neste momento. Primeiramente, o comprometimento com a possibilidade de fazer da prática investigativa um exercício de crítica permanente, um diagnóstico crítico do presente. Em aproximação de uma determinada tradição filosófica, Foucault auxilia-nos a tomar como objeto investigativo "a questão do tempo presente e daquilo que somos neste exato momento" (Foucault, 1995, p. 239).

A seguir, a segunda questão, que apresento como prerrogativa metodológica,é a opção por não partir de nenhum campo a priori para a produção deste estudo, mas, antes disso, assumir as práticas como espaços investigativos privilegiados. Pensar a partir das práticas implica um reconhecimento de sua contingência, produzida em relações não submetidas a teleologias ou transcendentalismos. Posicionar as teorizações foucaultianas como uma "filosofia da prática", como nos sugere Veiga-Neto (2006, p. 85), supõe a constituição de uma prática intelectual que "se fundamenta em nenhum a priori, exceto o a priori histórico, ela [filosofia da prática] se coloca, então, como uma prática avessa às metanarrativas da Modernidade [...]”.

A terceira questão metodológica que orienta esta produção situa-se no entendimento de que os estudos foucaultianos nos auxiliam a problematizar os modos pelos quais nos constituímos "sujeitos". Seja pelos discursos da ciência, seja pelas práticas institucionais, pelas racionalidades políticas do Estado ou, ainda, pelo modo

1 São inúmeros os estudos contemporâneos que têm operado com essa ferramenta investigativa; destaco para este momento, no cenário brasileiro, as pesquisas de Saraiva e Veiga-Neto (2009), Lopes (2009), Silva e Fabris (2010) e Silva (2011). 
como nos tornamos o que somos, Foucault provoca-nos a pensar as tecnologias de governo, que são capazes de converter uma multiplicidade aleatória de indivíduos em sujeitos. Em um texto tardio, ao sistematizar sua trajetória e afirmar a centralidade do sujeito em sua produção acadêmica, o filósofo apresenta dois sentidos para a palavra "sujeito": "sujeito a alguém pelo controle e dependência, e preso à sua própria identidade por uma consciência ou autoconhecimento" (Foucault, 1995, p. 235).

Para fins de atender meus objetivos para este texto, organizei-o em quatro seções. Na primeira, apresento uma breve revisão crítica dos conceitos de segurança, proteção e seguridade social, tomando como referência os estudos do filósofo Michel Foucault e do sociólogo Robert Castel. A seguir, na segunda seção, trato de examinar determinados elementos do discurso pedagógico de nosso tempo, alicerçados na perspectiva das comunidades como espaços de intervenção pedagógica, que tendem a fabricar "pedagogias de proteção". Na terceira seção, ao lidar com o material empírico selecionado para a referida pesquisa, procuro tornar visível uma das estratégias que entendo operar na produção da docência contemporânea no ensino médio, a saber: o gerenciamento dos riscos coletivos. Na quarta e última seção, examino outra estratégia privilegiada nessa analítica: os modos contemporâneos de autopropulsão ao medo. Defendo neste artigo a perspectiva de que a ação articulada dessas estratégias, ancoradas em pedagogias de proteção, propõe-se a fabricar uma docência socialmente relevante e politicamente útil para o ensino médio brasileiro.

\section{SEGURANÇA, PROTEÇÃO E SEGURIDADE SOCIAL: MULTIPLICANDO OLHARES}

Como é possível que possamos nos sentir coletivamente protegidos? Que dispositivos (sociais, políticos e econômicos) são colocados em ação na busca da segurança coletiva? Quais questões deveriam compor a formação dos sujeitos em um tempo de multiplicação do sentimento de insegurança? Que modelo de educação (e de professor) seria apropriado para essas condições? O sociólogo francês Robert Castel (2005, p. 9), em uma publicação recente, sugere que, historicamente, as sociedades modernas se constituíram "sobre o terreno da insegurança, porque são sociedades de indivíduos que não encontram, nem em si mesmos, nem em seu entorno imediato, a capacidade de assegurar sua proteção". Na medida em que os indivíduos não encontram proteção em si mesmos, toda busca de proteção está sempre associada ao próprio desenvolvimento da vida em sociedade. Em outras palavras, "a insegurança, em suma, é em grande parte o reverso da medalha numa sociedade de segurança" (idem, ibidem).

A Modernidade, inicialmente, deparou-se com os problemas da insegurança civil e da insegurança social. Do ponto de vista do primeiro problema, a solução encontrada foi a criação do Estado de direito. Uma vez que os indivíduos não estavam regidos por normas coletivas, vivia-se sob um risco permanente de "agressão física e de dissociação social” (idem, p. 14) e, consequentemente, necessitou-se de sistemas de regramentos da vida coletiva para que os indivíduos pudessem "fazer sociedade" (idem, p. 15). 
Em sua primeira formulação, desde Hobbes, o Estado moderno emerge como uma proteção contra a insegurança civil, pois, ainda que de forma absolutista, "liberta os indivíduos do medo e permite-lhes existir livremente na esfera privada" (idem, p. 16). Poucas décadas depois, o filósofo John Locke apresenta uma segunda possibilidade para o tratamento da questão. Na medida em que, com o Estado, o indivíduo não está mais diretamente ligado às redes tradicionais de proteção, é a propriedade que passa a exercer o fator de proteção coletiva. "A propriedade é o alicerce de recursos a partir do qual um indivíduo pode existir por si mesmo e não depender de um patrão ou da caridade de alguém" (idem, p. 18). Nessa configuração, a propriedade funciona como a principal garantia de independência e proteção dos indivíduos. Mas e aqueles que não eram proprietários? Que garantias de proteção coletiva possuíam?

Aqui nos deparamos com o segundo problema: a insegurança social. Em face das questões sociais da Europa do século XVIII, Castel mostra-nos como um contingente significativo da população tinha seu "estatuto social de indivíduo" ameaçado. Visto que a maioria das pessoas não era proprietária, não possuía proteções coletivas, nem mesmo garantias de subsistência, sua única possibilidade de independência social era o trabalho. A saída para essa situação foi atribuir proteções e direitos à condição de trabalhador, "portanto, em duas palavras: atribuindo proteções fortes ao trabalho; ou construindo um novo tipo de propriedade, concebida e posta em prática para assegurar a reabilitação dos não proprietários, a propriedade social" (idem, p. 32) A condição salarial, os direitos trabalhistas e os estatutos civis do trabalho fundaram aquilo que Castel nomeia como "sociedade salarial", considerando-a como "uma sociedade na qual a imensa maioria das pessoas tem acesso à cidadania social, primordialmente, a partir da consolidação do estatuto do trabalho" (idem, p. 33).

Em virtude de um conjunto de mudanças societárias transcorridas durante o século XX, entre as quais as reconfigurações no papel do Estado, fez-se possível notar que a questão da segurança/insegurança coletiva não estava apenas circunscrita ao regime civil e ao social. A insegurança denotava a própria condição moderna (Bauman, 1999; Castel, 2005). Conforme apresenta-nos Michel Foucault, em um de seus cursos ministrados no final da década de 1970, a vida social, em suas diferentes nuances, produziu-se regida por dispositivos de segurança. Seguirei tratando dessa temática, acompanhando o pensamento foucaultiano.

Ao apresentar a temática a ser abordada em seu curso no Collège de France, no ano de 1978, Michel Foucault propõe-se a examinar o conceito de segurança. Diferentemente da criação de um código legal, que gera leis e estabelece punições, ou mesmo de um mecanismo disciplinar, povoado por práticas de vigilância ou de correção, o século XVIII permitiu a constituição de novas racionalidades de poder. Sem estabelecer uma ruptura com os regimes da punição e da correção, anteriormente predominantes, as tecnologias de segurança produziram entendimentos mais globais e racionalizados para o tratamento dos fenômenos. Tais entendimentos procuraram situar os acontecimentos em uma série de probabilidades, fixaram uma média aceitável e desenvolveram um cálculo de custos para a compreensão e o tratamento da vida social (Foucault, 2008). 
O desenvolvimento das tecnologias de segurança, ${ }^{2}$ em suas diferentes técnicas, "consiste em boa parte na reativação e na transformação das técnicas jurídico-legais e das técnicas disciplinares" (idem, p. 13). Para elucidar essa afirmativa, Foucault toma inúmeros exemplos; um deles refere-se ao tratamento das epidemias. Até o final da Idade Média, as pessoas leprosas eram excluídas da convivência social. Essa exclusão era referenciada em um sistema jurídico-religioso que justificava a separação entre doentes e não doentes. Por outro lado, entre os séculos XVI e XVII, o modo de tratamento das pessoas com "peste" era caracterizado por outros instrumentos. As diferentes cidades produziam regulamentos sobre as formas de as pessoas conduzirem seu tratamento: alimentação, circulação nas ruas, modos de contatos e apresentação a inspetores eram alguns dos critérios normatizados nesses regulamentos. Foucault argumenta, de forma diferenciada em relação ao primeiro exemplo, marcado por um sistema jurídico, que se trata de um "sistema disciplinar". O terceiro exemplo utilizado pelo filósofo refere-se ao problema da varíola no século XVIII.

O problema se coloca de maneira diferente: não tanto impor uma disciplina, embora a disciplina [seja] chamada em auxílio; o problema fundamental vai ser o de saber quantas pessoas pegaram varíola, com que idade, com quais efeitos, qual a mortalidade, quais as lesões ou quais as sequelas, que riscos se corre fazendo-se inocular, qual a probabilidade de um indivíduo vir a morrer ou pegar varíola apesar da inoculação, quais os efeitos estatísticos sobre a população em geral, em suma, todo um problema que já não é o da exclusão, como na lepra, que já não é o da quarentena, como na peste, que vai ser o problema das epidemias e das campanhas médicas por meio das quais se tentam jugular os fenômenos, tanto os epidêmicos quanto os endêmicos. (idem, p. 14)

Por meio desse terceiro exemplo, o filósofo não pretende exibir uma sucessão - lei, disciplina, segurança -, mas demarcar a ênfase que as sociedades contemporâneas atribuirão à segurança como tecnologia política desde o século XVIII. Para elucidar essa tecnologia, Foucault, na primeira parte do curso de 1978, ainda faz uso da distribuição espacial das cidades e da escassez alimentar como exemplares históricos da emergência dessas novas práticas. Entretanto, ao final da aula de 18 de janeiro, Foucault desenvolve algumas diferenciações entre os dispositivos disciplinares e de segurança, as quais serão úteis para a argumentação desenvolvida nesta analítica.

Enquanto a disciplina procede de forma "centrípeta", produzindo regulamentos sobre o que a rodeia, a segurança desencadeia ações "centrífugas", ou seja, "trata-se portanto de organizar ou, em todo caso, de deixar circuitos cada vez mais amplos se desenvolverem" (idem, p. 59). Dito de outra maneira, enquanto a disciplina "não deixa escapar nada", os dispositivos de segurança "deixam fazer". Isso faz com

2 Para fins deste texto, opto por considerar as noções de segurança e seguridade como equivalentes. 
que a segurança esteja apoiada nos detalhes e em certo grau de liberdade. Enfim, enquanto a disciplina diz como as coisas devem ser feitas, a outra opera na regulação.

Em outras palavras, a lei proíbe, a disciplina prescreve e a segurança, sem proibir nem prescrever, mas dando-se evidentemente alguns instrumentos de proibição e de prescrição, a segurança tem por função responder a uma realidade de maneira que essa resposta anule a realidade a que ela responde - anule, ou limite, ou freie, ou regule. Essa regulação no elemento da realidade é que é, creio eu, fundamental nos dispositivos de segurança. (idem, p. 61)

Se a tecnologia de segurança opera na regulação - e não na prescrição -, a liberdade torna-se condição de sua implementação."A liberdade acaba por funcionar como ideologia e como técnica de governo" (idem, p. 63). Destarte, a segurança, ao mobilizar estratégias de regulação, efetua-se a partir da liberdade de cada um, isto é, a articulação liberdade-regulação torna possível a emergência das tecnologias de segurança.

Em consonância com a teorização foucaultiana, Castel (2005, p. 60) expõe que atualmente encontramos "uma nova geração de riscos, ou pelo menos de ameaças percebidas como tais: riscos industriais, tecnológicos, sanitários, naturais, ecológicos etc.”. Tais problemáticas, segundo o sociólogo, não têm ligação direta com as duas primeiras gerações de riscos coletivos descritas acima. Entretanto, três questões emergem de forma produtiva para este texto com base nessa abordagem teórica: a) percebe-se uma privatização das responsabilidades; b) buscam-se soluções locais e comunitárias para tais situações; c) a produção de riscos/medos coletivos articula-se aos desenvolvimentos tecnocientíficos e ao produtivismo desenfreado.

Como é possível notar a emergência das condições acima descritas nas pedagogias contemporâneas? De quais modos essas tecnologias de segurança se engendram na produção contemporânea da docência? Que saberes e poderes são colocados em circulação para a constituição de outros modos de tratamento das relações escolares no ensino médio? Trato dessas questões na seção a seguir, situando-as na emergência daquilo que aqui nomearei como "pedagogias de proteção". Tais pedagogias alicerçam-se na comunidade como espaço de intervenção, no gerenciamento dos riscos coletivos e na autopropulsão ao medo.

\section{A COMUNIDADE COMO ESPAÇO DE INTERVENÇÃO: PEDAGOGIAS DE PROTEÇÃO}

Pensar na comunidade como espaço de intervenção tem se apresentado como uma tendência nas sociedades contemporâneas. Diferentes programas nas áreas de educação, saúde, meio ambiente e criminalidade, entre outras, posicionam as comunidades como campos de intervenção privilegiados, sobretudo ao terem como horizonte uma sociedade democrática. Conforme sugerem alguns estudos (O’Malley, 2007; Popkewitz, 2009; Popkewitz; Olsson; Petersson, 2009), diferentes "qualidades performativas comunitárias" são evocadas na busca pela comunidade como espaço de educação preventiva, de formação cidadã e de intervenções políticas 
democráticas. "A comunidade representa um tema redentor no envolvimento e no empoderamento, no qual a resolução de problemas produz uma cidadania responsável" (Popkewitz; Olsson; Petersson, 2009, p. 86).

O’Malley (2007) argumenta que, sob a gramática do neoliberalismo, as comunidades destacam-se como foco de políticas de seguridade. Nesse sentido, tais espaços são apontados como mais comprometidos com seus membros; por melhor entenderem os seus problemas, por serem mais flexíveis e criativos que as instituições burocráticas, focalizam-se nas demandas e potencialidades locais, e suas atividades são mais "baratas" que os demais serviços públicos (idem). Dessa forma, faz-se possível perceber algumas articulações entre as comunidades e as novas políticas de seguridade. Políticas de gerenciamento de riscos, de perigos ou de medos coletivos, nesta analítica, são entendidas como tecnologias de governo, uma vez que se ancoram em estratégias de condução da conduta dos outros e de si mesmo. No que tange especificamente à educação de nosso país, amplio a discussão a seguir.

$\mathrm{Na}$ segunda metade do século XX, um conjunto de tendências teóricas procurou apresentar e problematizar as aproximações entre a instituição escolar e o mundo social mais amplo. Democracia, cidadania, autonomia, emancipação e participação foram alguns dos sentidos teleológicos para a educação produzidos nesses lugares teóricos. A premissa de que a educação somente faz sentido quando dialoga com os contextos sociais e/ou neles interfere marca uma importante tradição pedagógica brasileira, autointitulada como "progressista". Para situar como essa "docência comunitária" foi gestada no país, recorro, fazendo um breve exercício genealógico, às concepções pedagógicas de Álvaro Vieira Pinto, Paschoal Lemme e Paulo Freire, alguns dos principais pensadores da educação brasileira no século XX.

Paschoal Lemme (1988), em suas memórias, publicadas no ano de 1988, discute uma possibilidade educativa diferenciada para os processos conhecidos como instrução e ilustração. O autor entende que há uma forma de educação que passa pelos regimes formais de escolarização, mas vai além deles: a educação política. Um processo formativo com essa conotação permite que o indivíduo "passe a compreender a própria estrutura da sociedade em que vive, o sentido das transformações que estão se processando nela, e assim, de mero protagonista inconsciente do processo social, passe a ser um membro atuante na sociedade" (idem, p. 73). A ação pedagógica, dessa perspectiva, conduziria os diferentes sujeitos a intervenções nos contextos em que vivem.

O educar politicamente, proposto pelo pensador, toma como objeto prioritário "revelar ao indivíduo a verdade sobre o contexto social em que vive e sua posição nele, para que essa verdade exerça todo o poder mobilizador que somente a verdade possui" (idem, p. 74). Em nome dessa verdade, o alvo do processo de ensino dessa abordagem pedagógica é o povo, pois este precisaria exercer um controle mais efetivo sobre o ensino a que seus filhos estão submetidos. Tanto para essa parcela da população, quanto para os educadores e administradores públicos, o desafio posto está em posicionar o sentido dos processos pedagógicos para além da sala de aula, comprometendo-os com posturas políticas transformadoras.

Em direção aproximada, Álvaro Vieira Pinto (1982), em seu texto Sete lições sobre educação de adultos, ao demarcar as condições antropológicas e históricas da 
educação, pretende apresentar um compromisso orgânico entre as práticas escolarizadas e as práticas sociais. $\mathrm{O}$ autor retoma algumas clássicas dimensões das práticas educativas (processo, fato existencial, fato social, fenômeno cultural, atividade teleológica, entre outras). Entretanto, enuncia uma dimensão absolutamente diferenciada em relação à tradição pedagógica que o antecedeu. Vieira Pinto situa a educação como uma modalidade de "trabalho social".

A educação é parte do trabalho social porque:

- trata de formar os membros da comunidade para o desempenho de uma função no âmbito da atividade total;

- o educador é um trabalhador (reconhecido como tal);

- no caso especial da educação de adultos, dirige-se a outro trabalhador, a quem tenciona transmitir conhecimentos que lhe permitam elevar-se em sua condição de trabalhador. (idem, p. 39)

A articulação enunciada e visibilizada por Vieira Pinto entre educação, comunidade e trabalho social permite-nos reconhecer a educação como um campo de regulação da vida dos sujeitos em comunidade. A ideia de trabalho social implica uma ação sobre os outros, uma ação sobre agrupamentos humanos dispostos a aprender. Afora essa questão, importa pensar que o educar politicamente de Lemme (1988), articulado à educação como trabalho social de Vieira Pinto (1982), permite-nos avançar um pouco e pensar as aproximações entre educação e participação comunitária em Paulo Freire.

Em um texto do início da década de 1990, no período posterior àquele em que ocupou a Secretaria Municipal de Educação de São Paulo, Paulo Freire (1995) busca refletir como uma prática educativa crítica pode vincular-se à participação comunitária e/ou nela alicerçar-se. Inicialmente, destaca que "a prática educativa é uma dimensão necessária da prática social” (idem, p. 65-66). Dessa forma, a partir desse lugar, a prática educativa faz-se histórica e também política. Assim entendendo essa prática, Freire sugere um compromisso político do educador.

Agora bem, a impossibilidade total de ser neutros em face do mundo, do futuro - que não entendo como um tempo inexorável, um dado dado, mas como um tempo a ser feito através da transformação do presente com que se vão encarnando os sonhos - nos coloca necessariamente o direito e o dever de nos posicionar como educadores. $\mathrm{O}$ dever de não nos omitir. $\mathrm{O}$ direito e o dever de viver a prática educativa em coerência com a nossa opção política. Daí que, se a nossa é uma opção progressista, substantivamente democrática, devemos, respeitando o direito que têm os educandos de também optar, para o que precisam de liberdade, testemunhar-lhes a liberdade com que optamos (ou os obstáculos que tivemos para fazê-lo) e jamais tentar sub-repticiamente ou não impor-lhes nossa escolha. (idem, p. 69-70)

Diante de seu compromisso político, a pedagogia freiriana dirige a atuação dos educadores para a intervenção nas comunidades em que estão inseridos. A 
expressão designada para essa ênfase é "participação comunitária". São derivados dessa concepção conceitos e práticas como cidades educadoras, conselhos escolares, autonomia das escolas, planejamento participativo e avaliação emancipatória, entre outros. Trabalha-se com a premissa de que é dever de um educador progressista entender que "é a própria comunidade local que, tendo a escola como algo seu, se faz igualmente presente na condução da política educacional da escola" (idem, p. 74-75).

Parece-me que é no interior da matriz pedagógica progressista, desenvolvida no Brasil entre as décadas de 1950 e 1970, que se torna possível situar a emergência das comunidades locais como espaços de intervenção pedagógica. Construções teóricas, como as acima referidas, permitem a fabricação na educação brasileira de uma "pedagogia das proteções". Entendo que tal configuração pedagógica, ao situar-se no interior do jogo político das tecnologias de seguridade, toma as comunidades como espaços de intervenção pedagógica e propõe-se a regular a subjetividade docente.

No que tange a essa configuração pedagógica, gostaria de demarcar que, contemporaneamente, essa "pedagogia das proteções" produz um conjunto de deslocamentos em relação às teorizações progressistas da metade do século XX. ${ }^{3}$ Tal como discutirei posteriormente, tomando como base os materiais empíricos examinados, parece-me que a pedagogia das proteções está mobilizada em nosso tempo por uma individualização das responsabilidades e por políticas de gerenciamento dos riscos. O modo como a produção de docências comunitárias no ensino médio é enunciada e visibilizada na revista Carta na Escola, bem como as estratégias colocadas em ação, são descritos a seguir.

\section{DOCÊNCIA, ENSINO MÉDIO E GERENCIAMENTO DOS RISCOS COLETIVOS}

Ao estudar a seguridade como uma tecnologia de governo da docência no ensino médio, pude notar que tal tecnologia era engendrada por meio de pedagogias de proteção. Por essa expressão, nomeio um conjunto de estratégias pedagógicas que objetivam intervir nas relações entre escola e comunidade e que atribuem centralidade às experiências sociais e às condições existenciais dos sujeitos escolares. Assim sendo, não operam disciplinarmente, como as pedagogias produzidas desde o século XVII, mas privilegiam a regulação dos sujeitos e de seus modos de vida. ${ }^{4}$ Uma de suas estratégias de ação é o gerenciamento dos riscos coletivos, com base em iniciativas locais e/ou individualizadas. Por exemplo, de acordo com as recorrências do material empírico, os próprios sujeitos integrantes das comunidades escolares eram convocados a agir permanentemente no gerenciamento dos riscos

3 Sob a égide das políticas neoliberais, nas quais as responsabilidades sociais são individualizadas, as temáticas da proteção social e da participação comunitária são redimensionadas, em geral sendo aproximadas aos discursos sobre a equidade que perfazem as atuais políticas de escolarização.

4 No ensino médio são exemplares desse tipo de racionalidade pedagógica a avaliação por pareceres descritivos, as políticas de inclusão social, a organização dos currículos por projetos derivados da escolha dos estudantes e a ênfase na resolução de problemas. 
coletivos. Questões ambientais, questões de bem-estar coletivo ou mesmo de segurança internacional visibilizavam-se ao longo das edições da revista Carta na Escola como campos de intervenção das práticas pedagógicas escolares ou mesmo como conteúdos a serem pensados na organização curricular da instituição.

O tipo de ação governamental proposta nas enunciações do material conduziu-me a pensar que aquela estava situada no âmbito do gerenciamento. Não havia prescrições de conduta, normas ou imperativos a serem seguidos pelos docentes ou estudantes. $\mathrm{O}$ que se encontrava eram enunciações de estímulo à participação comunitária, modos de coordenação de tarefas e incentivos a práticas imediatizadas. Enfim, a revista tornava públicas algumas sugestões de pautas de ação a serem operacionalizadas contextualmente. A lógica do gerenciamento pressupõe que o docente opere como um mediador permanente; em outras palavras, ele se faz responsável pela gestão das aprendizagens, dos currículos, dos princípios institucionais e também das iniciativas comunitárias mobilizadas a partir da instituição escolar. Segundo Grinberg (2006, p. 71), "gerenciar não somente implica dispor os meios, mas também criá-los e articulá-los”.

Mais sofisticado que as práticas disciplinares e/ou administrativas nas instituições de ensino, o gerenciamento implica monitoramento contínuo.

A definição da gestão como planejamento e desenvolvimento de projetos justamente se dirige neste sentido: pensar a planificação já não como um ato prévio à ação, mas sim como uma prática que contempla e monitora constantemente aquilo que ocorre no desenvolvimento desta planificação. E, para isso, é necessário que os atores que antes eram posicionados como executores de planos, transformem-se, eles mesmos, em gestores. (idem, p. 72)

De forma articulada, torna-se possível apontar que as ações propostas para a gestão dos projetos ocorrem com base em uma lógica individualizada.

O caderno de Sustentabilidade da Carta na Escola inicia-se na edição de número 18 (2007a, p. 21) como uma iniciativa de todo o grupo editorial do qual a revista faz parte. As páginas integrantes do caderno foram impressas em papel reciclado e traziam temáticas diversificadas sobre o tema proposto. Na parte final, colocavam-se ações, projetos de pesquisa ou temas de discussão para os professores abordarem em sala de aula. A capa da primeira edição desse material (Imagem 1) dispõe de uma ilustração parcial do globo terrestre, em um fundo azul, com destaque para um conjunto de rachaduras em sua formação. É destacada a parte sul e central do continente americano. Na cor branca, salienta-se a manchete: "O planeta depende de você". Como legenda explicativa, aparece o seguinte texto: “Na empresa, em casa ou na vida política, cada um tem papel central na preservação do meio ambiente. Mudar padrões de consumo é mais simples e eficaz do que se imagina".

Imediatamente importa destacar duas conotações dessa imagem: o caráter individualizado da tomada de decisão e a questão dos riscos ambientais. Sobre o caráter individualizado, vale recorrer novamente a Castel (2005, p. 47), quando este sugere que, da mesma forma que nos novos modelos da produção e da organização do trabalho capitalistas, observam-se processos de "individualização-descoletivização". 


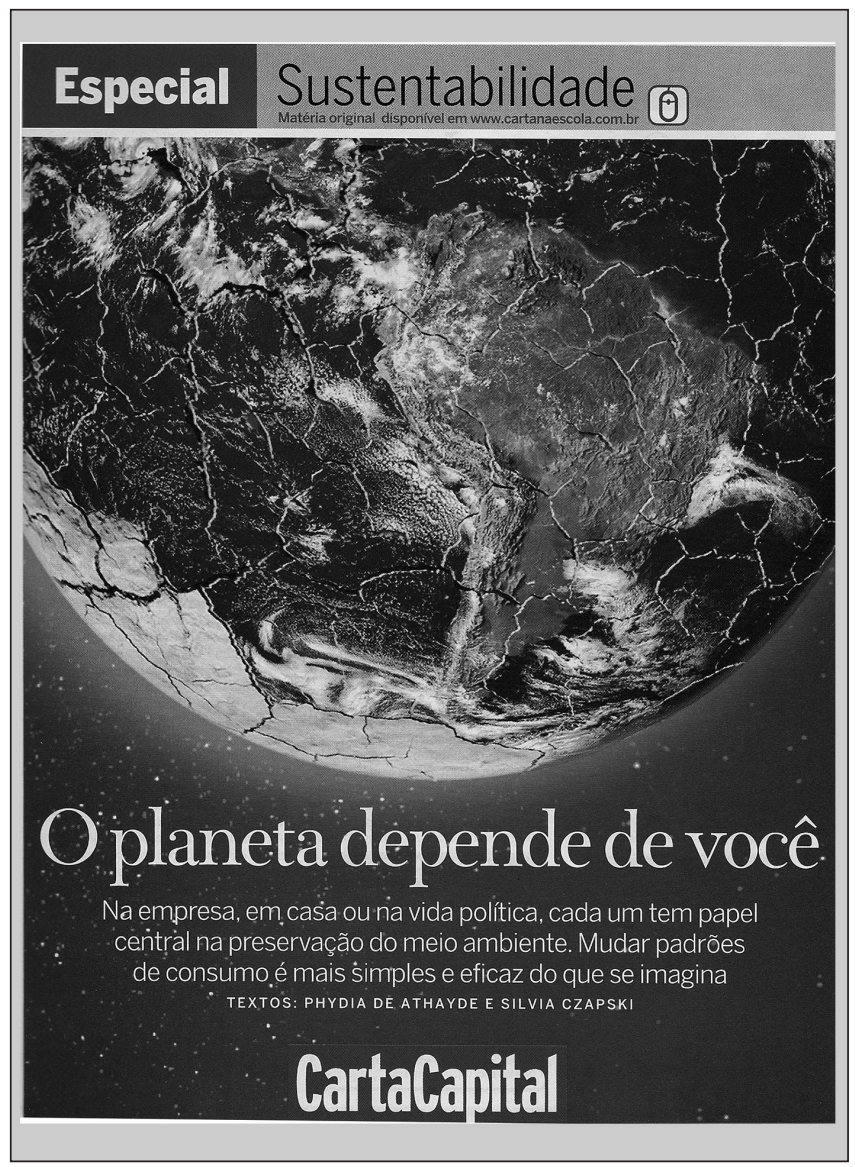

Imagem 1 - Carta na Escola, 2007a, p. 21.

Elaboração do autor.

Independentemente das problemáticas sociais, os sujeitos são responsabilizados pelas soluções de combate aos riscos e aos perigos da vida contemporânea. A busca pelas proteções, que mobilizou as práticas do Estado moderno, deriva para iniciativas privatizadas, e, paradoxalmente, segundo o sociólogo, os sujeitos sentem-se cada vez mais frágeis e atormentados pelo medo.

Existe uma relação estreita entre a explosão dos riscos, a hiperindividualização das práticas e a privatização dos seguros. Se os riscos se multiplicam ao infinito e se o indivíduo está só para enfrentá-los, cabe ao indivíduo privado, privatizado, fazer seu seguro próprio, se ele pode. Por conseguinte, o controle dos riscos não é mais um empreendimento coletivo, mas uma estratégia individual, enquanto que o futuro dos seguros privados é garantido através da multiplicação dos riscos. Sua proliferação abre um mercado quase infinito às seguradoras. (idem, p. 65-66) 
Quanto à questão dos riscos ambientais, Carta na Escola trabalha com a perspectiva de que experienciamos uma sociedade de risco permanente. A convivência em tal sociedade é apontada como a emergência das condições de um mundo incerto, um "mundo em descontrole", tal como sugere a conhecida expressão de Antony Giddens (1999). O sociólogo alemão Ulrich Beck (2006), um dos precursores dessa modalidade de análise social, argumenta que as incertezas da vida contemporânea são "fabricadas". "Essas 'verdadeiras' incertezas, reforçadas por rápidas inovações tecnológicas e respostas sociais aceleradas, estão criando uma nova paisagem de risco global" (idem, p. 5). O diagnóstico de Beck, ao tratar os riscos como "incertezas fabricadas", considera que as ameaças enfrentadas pela humanidade são creditadas “à própria 'modernização' e ao próprio 'progresso'” (idem, p. 7).

Não sabemos se vivemos em um mundo algo mais arriscado que aquele das gerações passadas. Não é a quantidade de risco, mas a qualidade do controle ou para ser mais preciso - a sabida impossibilidade de controle das consequências das decisões civilizacionais que faz a diferença histórica. Por isso eu uso o termo "incertezas fabricadas".

A atual percepção de que estamos vivendo em um mundo em descontrole, em suas diferentes mudanças, expõe a preocupação com os riscos globais da Modernidade, mas, ao mesmo tempo, sofistica os modos de regulação das subjetividades. O'Malley (2007) argumenta que análises como as de Beck se tornam problemáticas na medida em que se baseiam em concepções moralizantes. Temas como condições climáticas, problemas de saúde coletiva, catástrofes coletivas ou, mais simplesmente, vírus circulantes nas redes da internet são peculiares às pautas sociais deste tempo. Em Carta na Escola, visibilizam-se, com bastante recorrência, imagens fortes nesse sentido: o degelo das geleiras, o fim das neves eternas de determinadas montanhas, a desertificação, as secas ou grandes tempestades. O que interessa destacar é que, diante da lógica comunitária que perfaz sua ação pedagógica, o material sugere como desafio da escola de ensino médio tratar dessa problemática como um atributo da participação cidadã para o século XXI. Cabe reiterar que tal abordagem poderia servir de grade de inteligibilidade não apenas para o ensino médio, nosso objeto investigativo, mas a outros diferentes espaços educativos.

Sinais perturbadores, como a seca histórica da Amazônia, a furiosa temporada de furacões no Caribe e o fim das "neves eternas" do Kilimanjaro, mostram que a questão ambiental deixou de ser secundária, passando a ter papel principal, inclusive na formação educacional. Compreender o que se passa em nosso planeta e o que cada um pode (e deve) fazer já faz parte dos atributos profissionais e de participação cidadã de todo aquele que viver neste século 21 - que comę̧a quente. (Carta na Escola, 2006a, p. 4, grifos meus)

Os problemas de risco ambiental, em suas diferentes possibilidades, são posicionados como responsabilidade humana. A partir dos grandes avanços científicos e tecnológicos dos últimos dois séculos, o ser humano teria produzido uma 
exploração insustentável. Sem a pretensão de examinar a relevância política e social dessa questão, meu interesse está em mostrar como determinada tecnologia de governo emerge na condução da docência no ensino médio. A solução para amenizar os efeitos dessas catástrofes passa, justamente, pelas ações dos sujeitos individualizados, fomentadas nas comunidades onde as escolas estão inseridas. Sob essa gramática, torna-se desejável que posturas cidadãs, posturas críticas, enfim, posturas comunitárias sejam produzidas por meio da intervenção das instituições escolares.

Desmontar iniquidades, romper privilégios, rever direitos adquiridos, mesmo que à força, é tarefa de décadas. Significa contrariar interesses e repensar atitudes. É, de certa forma, o que também abordamos no Especial de Sustentabilidade, que aponta para outro tipo de exploração insustentável: a do homem sobre o planeta. Eé papel da escola mostrar tanto as injustiças sociais e seus possiveis cruzamentos com questões raciais quanto o descalabro que estamos fazendo ao consumir muito mais do que a Terra é capaz de suportar. Informados, podemos refletir sobre a melhor forma de agir. Esperamos, ao trazer assuntos como esses ao professor, contribuir com novos pensares sobre velhos pesares. (Carta na Escola, 2007a, p. 4, grifos meus)

$\mathrm{O}$ fragmento anterior nos permite encontrar o lugar dedicado aos espaços escolares, em geral, e aos professores em particular. Por meio da informação, podemos nos conscientizar sobre a melhor forma de agir, contribuindo para o futuro do planeta. Cabe um destaque com relação ao adjetivo "informados", que demarca um tipo de reflexão em que a informação se torna central para os processos formativos, secundarizando os conhecimentos e saberes sistematizados. Porém, sendo a informação um modo de atuação na formação dos sujeitos, a revista mais uma vez expõe um compromisso com seu público: os professores do ensino médio. Ao trazer essas pautas, a revista pretende contribuir para "novos pensares", que serão operacionalizados pelos docentes em suas comunidades.

O consumo é a temática privilegiada para a discussão com as comunidades. Uma educação para o consumo responsável é uma sugestão bastante recorrente em Carta na Escola. A edição número 18, em sua página 31, apresenta uma reportagem que se inicia com uma manchete bastante provocativa: "Qual é a sua pegada ecológica?". O objetivo desse texto é levar o professor a refletir com os estudantes sobre o consumo responsável. Ter uma "pegada ecológica" significa, nesse contexto argumentativo, avaliar seu estilo de vida e mudar seus hábitos, colaborando para melhorar o planeta.

Partindo de uma linguagem interpelativa ("Caro professor"), o texto sugere a constituição de uma pauta pedagógica que enuncia uma composição conceitual bastante potente aos propósitos desta analítica: sustentabilidade - educação sujeitos críticos - transformação social. Tal composição permite que se visibilizem com maior clareza algumas intencionalidades dessa estratégia: o gerenciamento dos riscos coletivos através de práticas escolares formais que objetivam a formação de um consumidor consciente e crítico que transforme o mundo em seu entorno (suas comunidades). 
Caro professor, o Especial de Sustentabilidade, publicado nas edições anteriores, aponta a sustentabilidade como meta para garantir a nossa sobrevivência e nos convida à seguinte reflexão: para ser construída, há a necessidade de cada cidadão ir além da mera consciência para efetivamente mudar suas atitudes diárias. Assim, educar passa a ter um papel fundamental no processo de formação de cidadãos críticos que saibam fazer de seus hábitos de consumo um caminho para a transformação social, através da ética e da solidariedade.

Neste contexto, consideramos como consumidor responsável aquele indivíduo que inclui uma série de questionamentos em seus hábitos de consumo e enxerga a relação entre as suas escolhas diárias e as questôes socioambientais presentes na sociedade atual. A partir dessa consciência, busca caminhos alternativos para atuar e apoiar relações produtivas e comerciais mais coerentes com aquilo que valoriza, como o respeito, o equilíbrio e a própria vida de todos nós e do planeta. (Carta na Escola, 2007a, p. 31, grifos meus)

O sujeito a ser constituído é um consumidor responsável, aquele que tem "pegada ecológica", que mobiliza esforços na direção de refletir sobre si mesmo - seus hábitos, sua conduta, sua grade de valores. As escolhas diárias desse indivíduo devem estar voltadas para o compromisso com sua comunidade. Transformação social, formação ética e cidadania crítica, argumentos típicos da pedagogia brasileira da segunda metade do século XX (como apontei anteriormente), integram a nova gramática do gerenciamento dos riscos ambientais. Dessa forma, a instituição escolar e seus professores são tomados como responsáveis por levar adiante essas demandas formativas.

Para a realização dessa tarefa, a reportagem traz uma sugestão de método de trabalho. Na medida em que o texto (Badue; Zerbini; Pistelli, 2007) é assinado por consultoras do Instituto Kairós, uma organização voltada para o consumo responsável e o comércio justo, os modos de atuação sugeridos são derivados da publicação da organização.

Dessa forma, propõe-se a promover o Enxergar - estimular a formação de indivíduos críticos; o Refletir - analisar essas percepções à luz dos valores humanos, da ética, da sustentabilidade ambiental e da justiça social; e, assim, Intervir em nome da construção de outro mundo possível. (Carta na Escola, 2007a, p. 31, grifos meus)

A sugestão metodológica aproxima-se bastante das metodologias críticas produzidas na educação brasileira nas últimas décadas. Basta que recordemos a proposição metodológica freiriana, "ação-reflexão-ação", ou mesmo a metodologia participativa das pastorais católicas, "ver-julgar-agir". Tal metodologia articula-se com os debates educacionais da conscientização, da emancipação, da cidadania crítica e da participação comunitária. Entretanto, há novas ênfases: o consumidor crítico e a intervenção comunitária. Essas novas ênfases permitem-nos compreender alguns dos modos pelos quais essa estratégia se mobiliza no interior de uma tecnologia de seguridade. Os sujeitos são conduzidos a pensar o mundo e a si mesmos a partir da grade do gerenciamento dos riscos. Ao mesmo tempo em que se enuncia a necessidade de uma educação comprometida com a sustentabilidade ambiental e a 
justiça social, indicam-se os percursos para que os sujeitos, professores e estudantes regulem suas atitudes, responsabilizem-se pelas atuais condições do mundo e se comprometam com novos valores comunitários.

Em articulação com essa estratégia de gerenciamento dos riscos coletivos, percebo uma segunda estratégia em operação nessa tecnologia de governo - uma autopropulsão ao medo. Continuando o percurso de apresentação das recorrências do material empírico, noto que, em diferentes espaços sociais, políticos, culturais, econômicos ou ambientais, os professores se deparam com conjuntos argumentativos que explicam a vida social em estado de crise permanente.

\section{EDUCAÇÃO E AUTOPROPULSÃO AO MEDO}

Em um texto do final da década de 1990, ao discutir os efeitos da globalização, o sociólogo Zygmunt Bauman (1999) problematiza a excessiva preocupação contemporânea com a segurança. Naquele contexto, o autor está tratando de fenômenos como a multiplicação midiática dos investimentos em segurança pública, no combate à criminalidade, na construção de novas prisões ou em novos dispositivos de segurança doméstica. Para além de pensar tais problemas em si mesmos, a reflexão do autor nos conduz à afirmação de que vivemos as condições de um tempo em que se generaliza e se intensifica a preocupação com segurança.

O efeito geral é a autopropulsão do medo. A preocupação com a segurança pessoal, inflada e sobrecarregada de sentidos para além de sua capacidade em função dos tributários de insegurança e incerteza psicológica, eleva-se ainda acima de todos os outros medos articulados, lançando sombra ainda mais acentuada sobre todas as outras razões de ansiedade. (idem, p. 127)

Acerca dessa questão, Bauman (2006), em uma entrevista recente, aponta que na atualidade estaríamos experienciando uma "síndrome de Titanic". Medos de colapsos, de crises coletivas ou mesmo de estados de "descivilização" nos conduziriam a essa condição temerária. "A síndrome de Titanic é o horror de cair através da "crosta fina' da civilização nesse vazio despido dos pontos elementares da vida organizada, civilizada" (idem, p. 17). A possibilidade de que estejamos sempre despreparados ou indefesos diante da vida social ou da natureza sustentaria a multiplicação contemporânea dos medos/riscos.

Servindo-me da abordagem sociológica de Bauman (1999), trabalho nesta analítica com a premissa de que as tecnologias de governo contemporâneas, mobilizadas sob a égide da seguridade, propõem-se a operar a partir do gerenciamento dos riscos coletivos (descritos anteriormente) e de uma "autopropulsão ao medo". Essa autopropulsão ao medo conduziria os sujeitos a preocuparem-se intensamente com seu futuro e o futuro das novas gerações, visto que o mundo se encontra em crise permanente. No interior da teorização pedagógica contemporânea, são inúmeras as obras que versam sobre essa tendência. $\mathrm{O}$ educar em tempos incertos, o educar em cenários de crise ou mesmo o educar para o século XXI, em muitos títulos de manuais pedagógicos hodiernos, tomam essa conotação. 
Acompanhando as recorrências dos excertos coletados em Carta na Escola, observo essa estratégia operando em espaços bastante heterogêneos, como o futuro do Brasil, a educação nacional, o saneamento básico, a tecnologização do mundo, a saúde coletiva, o mundo do trabalho e a ética empresarial. Neste momento, mostro algumas dessas recorrências.

Quanto à educação brasileira, em geral os textos e as entrevistas publicadas sugerem um estado de crise educacional permanente. Os processos de exclusão educacional, o ainda baixo nível educacional da população, os índices de evasão e repetência ou mesmo a violência escolar estariam vinculados a uma divida educacional do pais. Tais abordagens da revista, autodenominadas como críticas, sugerem que o Estado brasileiro, ao longo de sua história, privilegiou o investimento nas classes alta e média e priorizou muito pouco a educação das classes sociais mais desfavorecidas. Esse argumento, na maioria das vezes, estabelece comparações entre o Brasil e os demais países latino-americanos ou europeus. A autopropulsão ao medo operaria como uma consequência dessa abordagem: aqueles jovens que permanecem muito pouco tempo nas escolas tendem a inserir-se em trabalhos informais ou a lançar-se no mundo das drogas e da criminalidade.

Estratégias como as escolas de turno integral, o aumento do tempo de permanência dos jovens nas escolas ou ações de profissionalização imediata são sugeridas. Políticas como as escolas-parque, de Anísio Teixeira, ou os Centros Integrados de Educação Pública (CIEPS), de Darcy Ribeiro, vislumbram-se como ações de controle dessa situação, operando uma sensível redução de seu potencial pedagógico. O objetivo imediato dessa pauta pedagógica seria a seguridade social: permanecer maior tempo nas escolas, praticando esportes ou discutindo ações de cidadania, pode ser a solução para que os jovens não estejam diluídos nas perigosas condições urbanas de nosso país. Os fragmentos seguintes auxiliam-nos na visibilização dessa questão.

Tantos adiamentos ampliaram a dívida educacional do País. É preciso, agora, oferecer educação de qualidade, em um esforço para ampliar nossa escolaridade média, que atualmente patina em menos de cinco anos, enquanto a Argentina tem média de 8,8 anos. (Carta na Escola, 2006d, p. 4, grifos meus)

Dois educadores brasileiros, desses bons em teoria e prática, já defenderam essa medida e a vivenciaram: Anísio Teixeira, com suas Escolas-Parque na Bahia dos anos 1950, e Darcy Ribeiro, com os Cieps na década de 1980, no Rio de Janeiro. Para eles, e para Yves, mais tempo na escola beneficia, em especial, as crianças mais pobres, que fora da escola não encontram livros nem um bom ambiente de aprendizagem. Em contrapartida, o aumento no número de horas/aula abriria espaço para a prática de esportes, leituras e debates sobre temas de cidadania (a violência, por exemplo). (Carta na Escola, 2006c, p. 4, grifos meus)

Outra questão destacada em Carta na Escola, que nos remete à autopropulsão ao medo, é a do desemprego entre as populações mais jovens. A capa da edição de número 6, de maio de 2006, expõe uma fotografia de vários jovens em uma escola. Em meio a vários estudantes que interagem supostamente em situação cotidiana, a imagem atribui destaque a uma jovem com os braços cruzados e com uma expressão fisionômica pensativa. Em face da postura da jovem, lê-se a chamada principal da 
revista para aquela edição: "Cadê meu emprego?". A legenda da fotografia indica: "O fantasma do desemprego assombra os jovens - no Brasil, na França e em todo o mundo". A referida edição faz uma crítica ao desenvolvimento tecnológico contemporâneo, bem como às novas matrizes produtivas do século XXI, que não criaram condições de emprego para todos.

Como as escolas formarão estudantes para uma sociedade sem empregos? A que dinâmicas curriculares as escolas de ensino médio estarão submetidas, se as estruturas da escola não acompanham o desenvolvimento tecnocientífico e os estudantes não estão preparados para um mercado de trabalho volátil? Essas inquietações povoam os editoriais de Carta na Escola, em geral com diagnósticos como o que segue, que conduzem os docentes e os professores a um estado de preocupação significativa.

A voragem tecnológica do século XX engoliu diversas carreiras e profissöes. Também inventou outras, mas a conta é negativa. O sistema capitalista criou em sua dinâmica um estado de desemprego pleno, estrutural. Não haverá trabalho para todos. E a maioria dos jovens do Ensino Médio vive com intensidade crescente a angústia de receberem um mundo onde o trabalho muda de forma a cada estação. Ou a cada invenção. (Carta na Escola, 2006b, p. 4, grifos meus)

Da mesma forma que as mudanças sociais e tecnológicas são responsabilizadas por determinados processos, em outros são evidenciadas como investimento prioritário. Investimentos estes a todos os tipos de proteção coletiva: novos sistemas de segurança pessoal, melhoramentos genéticos, sistemas antivírus para computadores, sacolas plásticas de material orgânico, energias renováveis. Das condições culturais de uma autopropulsão ao medo, termo contrabandeado de Bauman (1999), as inovações tecnocientíficas, sobretudo aquelas discutidas no interior da escola, têm o compromisso de operar como dispositivos de proteção. Em consonância com isso, outras temáticas muito recorrentes são a invenção de novas vacinas e a racionalização do consumo de água e luz nas instituições escolares.

Como podemos ver na Imagem 2, na parte superior da página uma fotografia apresenta uma pessoa trabalhando em um laboratório. Sua vestimenta branca, bem como o conjunto de tubos de ensaio à sua frente, sugere que se trata de estudo em alguma ciência biológica. Ao centro da página, em fundo branco, apresenta-se o texto da reportagem, distribuído em duas colunas. A manchete do texto jornalístico é "Duro de matar". O subtítulo, mais explicativo, dá o caráter do texto que virá a seguir: "A cada ano, novas vacinas são produzidas no esforço contínuo de nos proteger das muitas alterações proteicas que o vírus da gripe pode sofrer". $\mathrm{Na}$ parte inferior, de forma centralizada, vê-se uma imagem ampliada pelas lentes de um microscópio. Com a leitura da legenda, notamos que se trata de uma visão microscópica do vírus da gripe.

A preocupação com grandes epidemias, com questões de saúde coletiva, dieta alimentar ou bem-estar físico estão na agenda pedagógica do material analisado. Para além de dar a conhecer determinadas informações (como no caso das vacinas) ou encaminhar o interesse dos estudantes e professores para determinadas problemáticas, parece-me que a questão está situada no desenvolvimento de algumas atitudes de intervenção no 


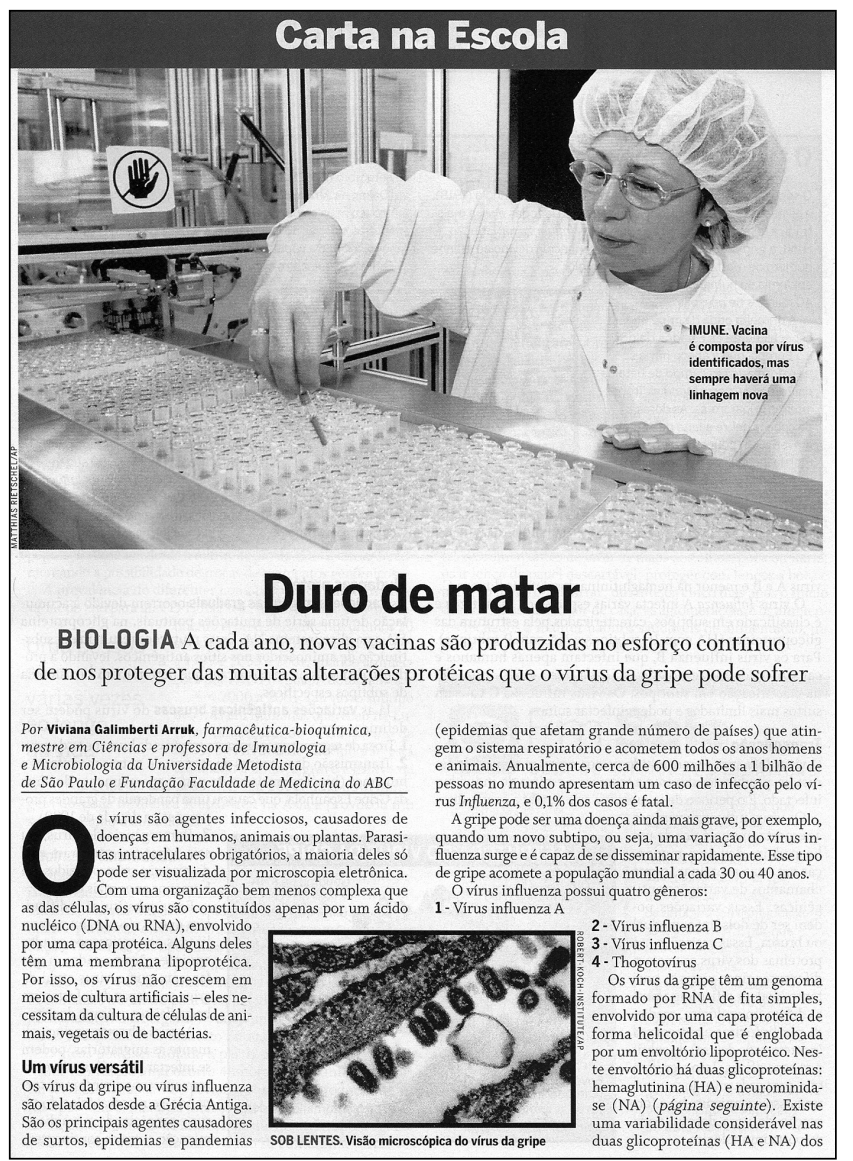

Imagem 2 - Carta na Escola, 2008b, p. 35.

Elaboração do autor.

mundo ao redor. $\mathrm{O}$ interesse está em articular possibilidades de aprendizagem, de economia e de intervenção nas comunidades escolares, como aponta o fragmento seguinte. A autopropulsão ao medo retroalimenta-se das campanhas de mobilização.

Racionalizar o consumo de água e luz na escola, espaço pedagógico por excelência, pode ser o resultado esperado de uma campanha que alie informação e mobilização. $\mathrm{E}$ a comunidade escolar poderia avançar nessa linha e criar seu próprio projeto de sustentabilidade ambiental, com coleta seletiva, reciclagem, uso de sobras alimentares para adubo da horta, alternativas energéticas discutidas em feiras de ciências junto às familias e à comunidade escolar etc. As possibilidades de economia e, principalmente, de aprendizagem são inesgotáveis. (Carta na Escola, 2007b, p. 4, grifos meus)

A tecnologia de seguridade, ao propor-se a conduzir a conduta dos professores do ensino médio, tende a produzir uma pedagogia das proteções que 
toma as comunidades (escolares, locais e até globais) como espaço privilegiado de intervenção. Tal configuração pedagógica mobiliza, pelo menos, duas estratégias: o gerenciamento dos riscos coletivos e a autopropulsão ao medo. Ainda que em muito inspiradas nas pedagogias progressistas, desenvolvidas no país desde a segunda metade do século XX, aqui se percebem alguns deslocamentos, sobretudo no que tange à proliferação dos sistemas de risco e à individualização das responsabilidades coletivas. Essa pedagogia das proteções, por meio de sua rede de atuação política, tende a regular as práticas escolares, delineando o espaço de atuação de seus públicos e os conhecimentos a serem estudados.

Cabe destacar que minha intenção não esteve em atribuir juízos de valor a essas emergentes pedagogias, visto que reconheço sua relevância em nosso tempo, mas busquei descrever os cenários políticos e econômicos nos quais elas são fabricadas, bem como os sistemas de raciocínio pedagógico por elas mobilizados. De agora em diante, desafio-me a seguir investigando as implicações pedagógicas e curriculares dessas pedagogias de proteção na composição e na organização das políticas de escolarização brasileiras. Para finalizar, reitero que, tal como descrevi nesta analítica, produzir no interior de uma docência comunitária implica o desencadeamento de práticas de governo de si e dos outros, as quais visem a uma intervenção qualificada no ensino médio com base nos valores da sustentabilidade ambiental e da justiça social, desencadeando tal configuração docente como politicamente útil.

\section{REFERÊNCIAS}

Badue, Ana; Zerbini, Fabiola; Pistelli, Renata. Qual é sua pegada ecológica? Carta na Escola, São Paulo: Editora Confiança, n. 18, p. 31, jun. 2007.

Bauman, Zygmunt. Globalização: as consequências humanas. Tradução de Marcus Penchel. Rio de Janeiro: Jorge Zahar, 1999.

. A síndrome de Titanic e os seus medos. IHU Online, São Leopoldo: Instituto Humanitas; Unisinos, ano IV, n. 182, p. 13-24, maio 2006. Disponível em: <http://www. ihuonline.unisinos.br/media/pdf/IHUOnlineEdicao181.pdf>. Acesso em: 20 jul. 2006. BECK, Ulrich. Incertezas fabricadas. IHU Online, São Leopoldo: Instituto Humanitas; Unisinos, ano IV, p. 5-12, maio 2006. Disponível em: <http://www.ihuonline.unisinos. br/media/pdf/IHUOnlineEdicao181.pdf >. Acesso em: 20 jul. 2006.

CARTA NA EsCOLA. São Paulo, n. 3, p. 4, jan./fev. 2006 a.

. São Paulo: Editora Confiança, n. 5, p. 4, abr. 2006 b.

. São Paulo: Editora Confiança, n. 6, p. 4, maio 2006c.

. São Paulo: Editora Confiança, n. 9, p. 4, set. 2006d.

São Paulo: Editora Confiança, n. 18, p. 4, 21 e 31, jun. 2007 a.

. São Paulo: Editora Confiança, n. 22, p. 4, dez. 2007b.

. São Paulo: Editora Confiança, n. 25, p. 2, abr. 2008a.

. São Paulo: Editora Confiança, n. 27, p. 35, jun. 2008b.

Castel, Robert. A insegurança social: o que é ser protegido? Petrópolis: Vozes, 2005.

DeAn, Mitchell. Governmentality: power and rule in modern society. Londres: Sage, 1999. 
Foucault, Michel. O sujeito e o poder. In: Dreyfus, Hubert; Rabinow, Paul (Orgs.). Michel Foucault. Uma trajetória filosófica: para além do estruturalismo e da hermenêutica. Rio de Janeiro: Forense Universitária, 1995. p. 231-249.

Segurança, território, população. São Paulo: Martins Fontes, 2008.

Freire, Paulo. Política e educação. 2. ed. São Paulo: Cortez, 1995.

Giddens, Antony. Mundo em descontrole. São Paulo: Record, 1999.

GrinberG, Silvia. Educación y gubernamentalidad en las sociedades de gerenciamento. Revista Argentina de Sociologia, Ciudad Autónoma de Buenos Aires: Consejo de Profesionales en Sociología, v. 4, n. 6, p. 67-87, 2006.

Lemme, Paschoal. Memórias. São Paulo: Cortez, 1988.v. 3.

Lopes, Maura Corcini. Políticas de inclusão e governamentalidade. Educação e Realidade, Porto Alegre: UFRGS, v. 34, n. 2, p. 153-169, 2009.

O'MALley, Pat. Experimentos en gobierno: analíticas gubernamentales y conocimiento estratégico del riesgo. Revista Argentina de Sociología, Ciudad Autónoma de Buenos Aires: Consejo de Profesionales en Sociología, v. 5, n. 8, p. 153-173, 2007.

Popkewitz, Thomas. El cosmopolitismo y la era de la reforma escolar. Madrid: Ediciones Morata, 2009.

Olsson, Ulf; Petersson, Kenneth. Sociedade de aprendizagem, cosmopolitismo, saúde pública e prevenção à criminalidade. Tradução de Marcelo de Andrade Pereira. Educação e Realidade, Porto Alegre: UFRGS, v. 34, n. 2, p. 73-96, 2009. Saraiva, Karla; Veiga-Neto, Alfredo. Modernidade líquida, capitalismo cognitivo e educação contemporânea. Educação e Realidade, Porto Alegre: UFRGS, v. 34, n. 2, p. 187-201, 2009.

Silva, Roberto Dias da. Empreendorismo e gestão dos talentos na constituição dos universitários contemporâneos. Linhas Críticas, Brasília:UnB, v. 17, n. 34, p. 545-560, 2011. Fabris, Elí Terezinha Henn. O jogo produtivo da educabilidade/ governamentalidade na constituição de sujeitos universitários. Revista Brasileira de Educação, Rio de Janeiro: ANPEd; Campinas: Autores Associados, v. 15, n. 44, p. 352$-363,2010$.

Veiga-Neto, Alfredo. Na oficina de Foucault. In: Kohan, Walter Omar; Gondra, José (Orgs.). Foucault 80 anos. Belo Horizonte: Autêntica, 2006. p. 79-91.

Vieira Pinto, Álvaro. Sete liçôes sobre educação de adultos. São Paulo: Cortez, 1982.

\section{SOBRE O AUTOR}

Roberto Rafael Dias da Silva é doutor em educação pela Universidade do Vale do Rio dos Sinos (UNISINOS). Professor da Universidade Federal da Fronteira Sul (UFFS).

E-mail: robertoddsilva@yahoo.com.br 